\title{
APPLICATIONS OF SRIVASTAVA-ATTIYA OPERATOR TO THE CLASSES OF STRONGLY STARLIKE AND STRONGLY CONVEX FUNCTIONS
}

\author{
J. K. Prajapat and S. P. Goyal
}

Abstract. Srivastava-Attiya operator is used to define some new subclasses of strongly starlike and strongly convex functions of order $\beta$ and type $\alpha$ in the open unit disk $\mathbb{U}$. For each of these new function classes, several inclusion relationships are established. Some interesting corollaries and applications of the results presented here are also discussed.

Mathematics subject classification (2000): 30C45, 11M35.

Keywords and phrases: Analytic functions, strongly starlike functions, strongly convex functions, Hurwitz-Lerch zeta function, Srivastava-Attiya operator, inclusion relations.

\section{REFERENCES}

[1] J. W. AleXANDER, 1 Functions which map the interior of the unit circle upon simple regions, Ann. of Math., 17 (1915), 12-22.

[2] S. D. Bernard, Convex and starlike univalent functions, Trans. Amer. Math. Soc., 135 (1969), 429-446.

[3] T. M. FLETT, The dual of an inequality of Hardy and Littlewood and some related inequalities, J. Math. Anal. Appl., 38(1972), 746-765.

[4] I. B. JUnG, Y. C. KIM AND H. M. SRIVASTAVA, The Hardy space of analytic functions associated with certain one-parameter families of integral operators, J. Math. Anal. Appl., 176 (1993), 138-147.

[5] J. L. LiU, A linear operator and strongly starlike functions, J. Math. Soc. Japon, 54, 4 (2002), 975981.

[6] M. Nunokawa, On properties of non-Carathéodory functions, Proc. Japan Acad. Ser. A Math. Sci., 68 (1992), 152-153.

[7] D. Raducanu AND H. M. SRIVAstava, A new class of analytic functions defined by means of convolution operator involving the Hurwitz-Lerch Zeta function, Int. Trans. Spec. Funct., 18, 12 (2007), 933-943.

[8] H. M. SRivastava And A. A. AtTiYa, An integral operator associated with the Hurwitz-Lerch zeta function and differential subordination, Int. Trans. Spec. Func., 18, 3 (2007), 207-216.

[9] H. M. SRivastava And J. Choi, Series Associated with the Zeta and Related Functions, Kluwer Academic Publishers, Dordrecht, Boston and London.

[10] H. M. SRIVAstava And S. Owa, Current Topics in Analytic Function Theory, World Scientific Publishing Company, Singapore, New Jersey, London and Hongkong, 1992. 